\title{
The Influence of MOOC on the Computer Teaching Courses in Colleges
}

\section{and Universities and the Improvement Measures}

\author{
Xu Bing ${ }^{1}$, Mou Kefen ${ }^{2}$, Fang Gang ${ }^{1}$ \\ 1.Chongqing Three Gorges University, China \\ 2.Middle School of Zhoujia, Wanzhou Chongqing,China \\ Xb_2316@163.com
}

Keywords: MOOC; computer course teaching; MOOC reform

\begin{abstract}
MOOC on-line, which is bound to have a profound impact on the teaching methods of computer courses in our country. Based on the in-depth study of MOOC, this article points out the advantages and disadvantages of MOOC. Meanwhile, it proposes improvement methods on the curriculum design and implementation, improving the ability of teaching students in accordance with their aptitude, innovating computer teaching methods by the networking characteristics of MOOC, and perfecting MOOC credit certification.
\end{abstract}

\section{MOOC}

MOOC (Massive Open Online Course) originated in 2007, Utah State University professor David Wiley had created a Wiki-based open network course "Intro to Open Education (INST 7150)" [1]. In 2008, Canada Dave Cormier and Bryan Alexander proposed the term of MOOC [2], and then, with applying the concept of MOOC Canadian scholars George Siemens and Stephen Downes first designed the MOOC courses in the true sense: Connectivism and Connective Knowledge Online Course (CCK08). In 2011, Stanford University professor tentatively freed to publish professor Andrew Ng's Machine Learning course online, more than 100,000 students from around the world signed up for this course. February 2012, Stanford University computer professor Sebastian Thrun and his colleagues David Stavens and Mike Sokolsky co-founded MOOC profit organization Udacity. April 2012, American Stanford University professor Daphne Koller and Andrew Ng, co-founded MOOC-profit organization Coursera [3]. May 2012, Massachusetts Institute of Technology and Harvard University jointly made investments and created the non-profit organization EdX. Coursera, Udacity and edX are three typical American MOOC platforms, MOOC Three Giants. Foreign Universities Princeton University, University of Michigan, University of Pennsylvania, the University of Washington have released MOOC courses. 2012 was called "The First Year of MOOC" by New York Times. [4].

\section{Advantages and Disadvantages of MOOC Courses}

\subsection{Advantages of MOOC Courses}

Large number of people joining the courses, not confined to only simple video lectures, but also blogs, web sites, social networking and other platforms, and there are no strict time requirements, all those are the characteristics of the MOOC's model. 
MOOC is a new type of learning and teaching methods, it has the following advantages: easy to use; low cost, the vast number of MOOC is free; covering a wide range; autonomous learning; and rich learning resources.

\subsection{Disadvantages of MOOC Courses}

2.2.1 The incapability of grasping the methods of teaching students in accordance with their aptitude.

Regrettably because of the vast number of students the very talented are being held back. The teacher-student relationship is closer in traditional teaching, teachers can fully understand the personality of students learning, to teach students in accordance with their aptitude, to guide students; however, in a MOOC classroom, it's impossible to make a full analysis of every student, and so probably outstanding students would be ignored without encouragement and concern.

2.2.2 It is not ideal for students with poor learning initiative

Allow learners to create their own contents, they may feel at a loss without a clue; learners need to adjust their learning, for those learners with relatively poorer learning initiative, the teaching effect may not be ideal, etc.

2.2.3 MOOC lack of social experiences

Although compared to the traditional Internet educational models MOOC's model has been improved, many educators still feel that the pure Internet-based education, is unable to achieve the advantages of traditional universities have in the interaction between students and teachers, and the overall teaching atmosphere. After all, the contents of college Students' learning not only the curriculum itself, but also a lot of collective social experiences, the main reason why going to the university to study is that it can help you grow and learn how to live and work [5].

2.2.4 Communication between teachers and students is not timely

According to statistics, the number of MOOC learners is relatively large, so the interactions between teachers and students in the course are difficult to achieve, taking into account of all students is almost impossible, as a result, questions and answers exchanges between teachers and students are inevitably not as timely as that in the traditional teaching ways, hence every student's opportunity to communicate with the teacher would be shared.

2.2.5 Extremely high course withdrawal rate.

The high rate of course withdrawals is a common problem in MOOC. We believe that the imperfect mechanism of students dropping out classes brings the curriculum disaster, especially when calculating the course registration number, pass rate of exams, excellent score's rate and doing the curriculum popularity evaluation, it is also a problem worth considering.

\section{MOOC Improvement Measures on Computer Teaching Courses in Colleges and Universities}

As a new network teaching model, MOOC has a broad development space and potential. In our country, the MOOC platform is still in the embryonic stage, so the impact of MOOC on the university computer course teachings have not been reflected. However, with the continuous development of MOOC platform, MOOC curriculum will certainly have a profound impact on the teachings and reforms of computer courses in our country. Therefore, we think MOOC computer course teachings in Colleges and universities can be improved from the following aspects.

\subsection{Curriculum Design and Implementation}

In order to achieve better teaching results, first of all before the commencement should upload the information about the syllabus and curriculum of the computer courses in MOOC. This will allow students to fully understand the curriculum, and have a greater interest in learning, but also to 
a certain extent, to reduce the withdrawal rate. Secondly, set the module and schedule for the study of the course. This allows students to grasp time and progress with skill and ease. When go to the lecture, when to test, when question and reasonably arrange other MOOC classes, but also allows teachers to grasp the entire course in real time, fully design the teaching contents and guidance time, to further stimulate the enthusiasm of students.

\subsection{Improve the ability of teaching students in accordance with their aptitude}

In MOOC platform the teaching contents and teaching methods are very novel, but having an indepth understanding of the content takes a lot time of deep thinking. Even though the course is free, the lack of outside guidance causes too many difficulties and interferes with completion of the courses. When encountering difficulties in learning, they may easily give up halfway by underestimating free curriculum value and trouble of seeking answers to the problem. This requires a high level of perseverance, awareness, understanding and learning ability of students, a large number of students are also trapped in this. The complexity of the traditional curriculum learning withdrawal mechanism, real-time teacher answering and frequent discussion between students can eliminate a lot of students dropping out from classes. Therefore, to promote the application of MOOC in computer teaching courses they must improve the ability of teaching students in accordance with their aptitude in MOOC platform. In this context, according to the number of participants in the course to increase the number of teaching assistants, to achieve the classification of mass submitted questions and answers, to automatically reply to duplicate questions, etc., which has a high demand for the ability of the MOOC platform software. In addition, according to the local registration numbers, introduce local teaching assistants to participate in the discussions or even offline parties, to create a strong learning atmosphere, so that MOOC students can be released from the lonely network terminal. In addition, you can also increase the number of rewarding incentives (such as, issue excellent course certificate), to improve the completion rate of the course [6].

\subsection{Using the network characteristics of MOOC to innovate computer teaching measure}

Traditional computer courses teaching models make the teachers and students stay in the same room, and when teachers give classes students often only listen rather than participate in the course, which is the opposite of course experiment, where students learn computer course by themselves and teachers only check the answers without participating. MOOC network enables teachers in teaching process to do computer experiment such as programming and operating with the students, directly combine classroom teaching with laboratory exercises, and teachers can check the experimental process of students in real time with the help of MOOC platform, answer immediately or adjust course contents based on feedbacks, and switch to "full-duplex" model of traditional computer teaching from "half duplex" model.

\subsection{Perfect MOOC credit certification}

Three MOOC platforms also gradually issue the course certificates to the curriculum learners, colleges and universities that participate in MOOC platform construction more than willing to recognize MOOC courses, agree to the conversion for college credit. American public and private educational certificate authorities are starting the evaluation on whether MOOC course can achieve university level or not. If MOOC indeed can reach university level, it can be converted to credit and proof of promoting learners taking the courses, which is bound to bring a huge impact on the teaching of computer courses, but also a great change in the way of learning computer courses. As China's MOOC construction is still in its infancy, which to a certain extent, restricts the promotion of MOOC courses in the computer course teaching. Under current system of higher education in our 
country, to verify MOOC courses, we can take learning evaluation of "online courses and offline evaluation" and credit certification system, that any registered students (including college students and non-students self-learners) can freely sign computer courses in MOOC platform, and colleges and universities make assessments with the traditional assessment methods, college students' exam scores can be included in the credits, while non-students self-learners can obtain the corresponding qualification certificates. This kind of learning evaluation method is not only conducive to the initial solution of the credit certification issue of computer courses teaching in colleges and universities in our country, but also easily solve the problem of examination integrity, in line with the current situation of China's higher education.

\section{Summary}

MOOC has developed rapidly in the world in recent years. Despite its limitations, it has obvious advantages in the computer courses, especially in the teaching of computer courses. In the new round of teaching reform of computer courses, to learn the advantages and improvement measures of MOOC platform, will certainly have a positive impact on the improvement of teaching quality.

\section{Acknowledgment}

This work is partially supported by Project Supported by Chongqing Cutting-edge and Applied Foundation Research Program (Grant No. cstc2014jcyjA40035), Project Supported by Scientific and Technological Research Program of Chongqing Municipal Education Commission (Grant No.KJ1401010).

\section{Reference:}

[1] Martin, F.G.Will Massive Open Online Courses Change How We Teach?[J]. Communications of the ACM, 2012, 55(8): 26-28.

[2] Li Qing, Wang Tao .MOOC: communicating in a Huge open curriculum model based on doctrine [J] China Distance Education, 2012, (3): 30-36.

[3] McAuley, A., Stewart, B., Siemens, G., and Cormier. D. "The MOOC Model for Digital Practice", University of Prince Edward Island, Social Sciences and Humanities Research Council's Knowledge Synthesis

Grants on the Digital Economy(2010) [EB/OL]. http://davecormier.com/edblog/wpcontentuploads/MOOC_Final.pdf, 2012-12-05.

[4] Coursera[EB/OL]. https://www.coursera.org/,2012-12-05.

[5] The New York Times. The Year of the MOOC[EB/OL]. http://www.nytimes.com/2012/11/04/education/ Edlife/massive-open-onlinecoures-are-multiplyingat-t-rapid-pace.html, 2012-12-05.

[6] Zeng Mingxing, Zhou Qingping, Caiguo Min, Wang Xiaobo, Chen Shengping, Huang Yun, Dong Feng Jian, based on the flipped classroom teaching mode research of MOOC. "China Educational Technology" 2015.4 